\title{
How State Education Agencies Acquire and Use Research in School Improvement Strategies
}

Policymakers have urged state education agencies (SEAs) to engage with organizations outside of their agencies to extend their capacity and to help them collect and use research to support school improvement. However, little is known about how SEAs search for, select, and use research in their school improvement efforts.

In the first study to examine communication structures, social capital, and information networks within SEAs, researchers Goertz, Barnes, and Massell in How State Education Agencies Acquire and Use Research in School Improvement Strategies applied social network perspectives and methods to identify knowledge sources utilized by SEAs. Their findings provide important insights into how SEA staff search for and incorporate research in their work and provide guidance to SEAs and policymakers on ways to apply these findings.

SEA staff gravitated to research that they perceived as relevant to their context, actionable, feasible, and helpful in addressing pressing problems of policy and practice, sometimes called "research designed for use."

Goertz, Barnes, \& Massell (2013)

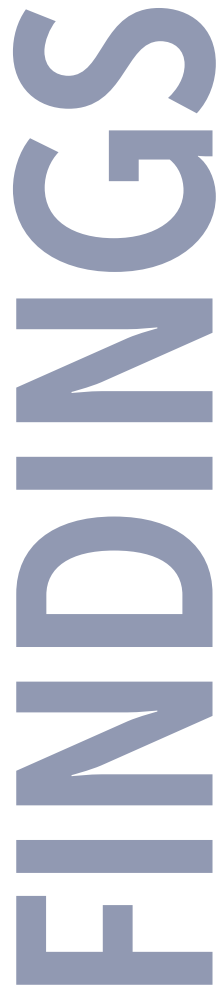

The findings focus on how three SEAs acquired and used research-based, evidencebased, and practitioner knowledge in their school improvement policies and programs:

" SEA staffs actively sought and were receptive to research ideas from within and outside their agencies. Typically this search reached across SEA offices, reflecting the cross divisional work of school improvement.

" About one-third of SEA staff reached out to a broad array of external organizations for research information on school improvement, particularly the federal government, professional membership associations, and institutions of higher education. SEA staff often turned to their existing network of resources to access research and new ideas.

» External organizations offered expertise and human capital; translated, synthesized, and packaged research; provided access to ready-made tools; and validated that actions were in step with research and/or practices of other states.

"SEAs used research to design and refine school improvement frameworks, strategies, and tools related to school improvement assistance. But research use was a twoway street. While broad research networks facilitated the flow of new ideas, a small number of key SEA staff worked in small groups with each other, external partners, and practitioners to make sense of research findings and adapt them to their local context. 


\section{SEAs' External Resources for Research Knowledge}

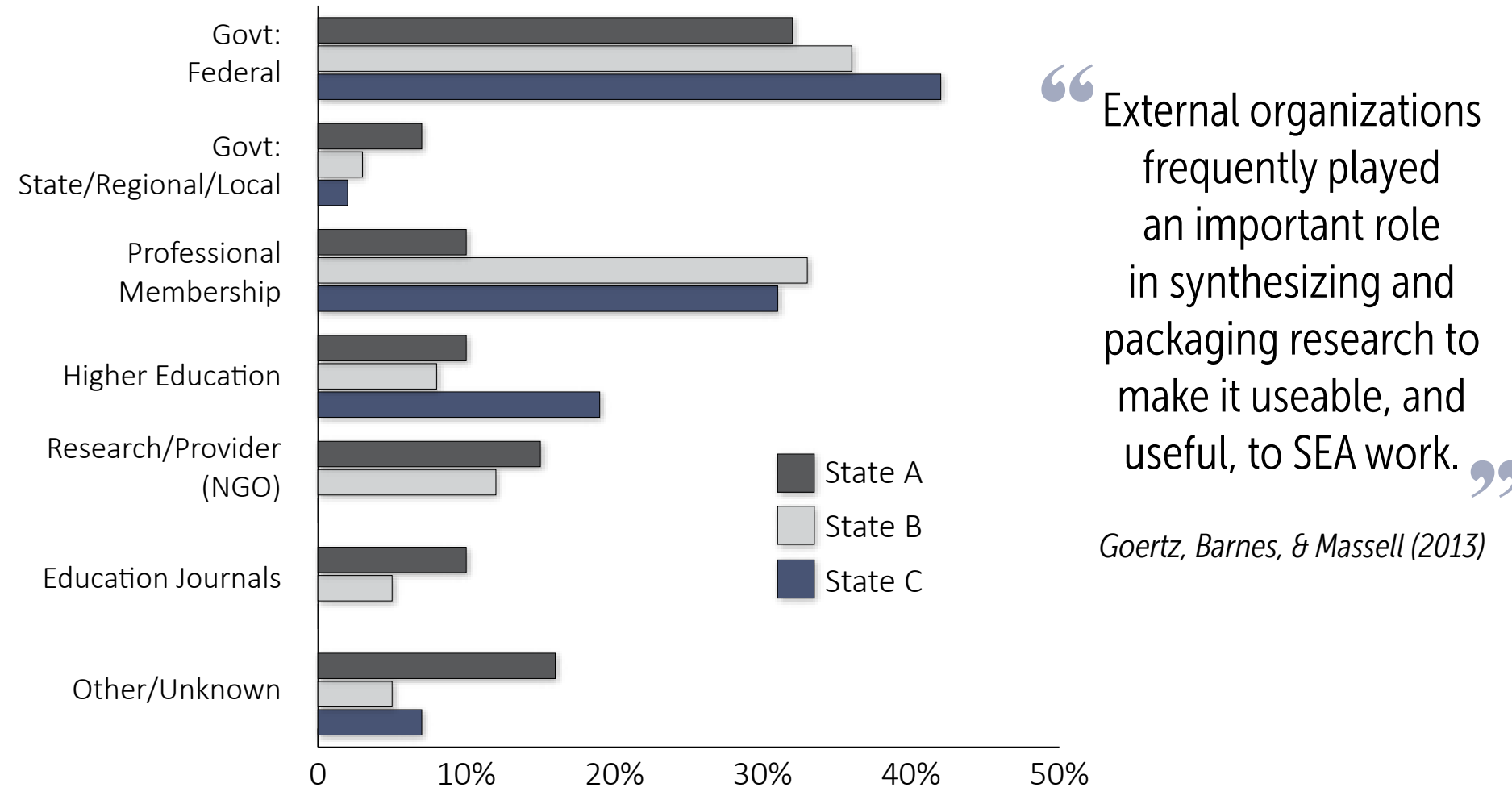

\section{Implications}

1. SEAs should draw on the infrastructure outside their boundaries, such as technical assistance centers, professional organizations, and universities, to access research and research designed for use.

2. SEAs should identify and connect knowledge brokers in their agencies and in external organizations who work on common problems.

3. SEAs should build a culture of research use, and build the capacity of their staff to broker research search and use and to assess the quality of research and researchbased products they access.

4. Policymakers should encourage and support SEA evaluations of their own programs to provide critical feedback to SEA staff.

\section{Questions? Find more info}

Contact Margaret Goertz at pegg@gse.upenn.edu. Read the full policy brief at http://cpre.org/sea-brief. Subscribe to Insights, CPRE's monthly e-newsletter.
The Consortium for Policy Research in Education (CPRE) brings together education experts from renowned research institutions to contrinbute new knowledge that informs Prek-16 education policy and practice. Our work is peer-reviewed and open-access. Visit cpre.org. 